\title{
CREATING HOME FOR STUDENTS OF COLOR: A QUALITATIVE STUDY
}

\author{
OWEN SETIAWAN
}

The St. Thomas Aquinas-University of Pennsylvania Partnership

\section{ABSTRACT}

My name is Owen Setiawan, and I am an IndonesianAmerican eighth grader. This piece is a reflection on a qualitative research study I worked on with a group of students that investigated how school climates feel for middle, high school, and college students of color in the United States. After analyzing data from interviews and personal reflections from my student team, I then present the specific ways in which and reasons why students of color feel comfortable or uncomfortable in different educational settings. I conclude with recommendations for making educational spaces more welcoming and home-like for diverse populations.
KEYWORDS

school climate, youth of color, discrimination

I N T RODUCTION

My name is Owen Setiawan, and I am an eighth-grade student at the Folk Arts Cultural Treasures Charter School in Philadelphia, Pennsylvania. This past summer at the University of Pennsylvania Graduate School of Education, I participated in a College Access program in which I was grouped with six other students from different Philadelphia high schools. This program was a component of the University of Pennsylvania-St. Thomas Aquinas Center partnership and developed out of a need from communities around the city to help students navigate the college admissions process while also providing a space for inquiry. My groupmates were Mei Prasetio, Erick Perez, Kerry Coles, Erin Santosa, Zaakirah Farnum, and Array Brown. We are all students from heavily encultured backgrounds, bringing our experiences from African-American, Latino/a, and Indonesian communities to easily connect as a group. Aside from thinking about the topic of college access in the United States, our goal was to investigate important issues in our lives and in the lives of many students in Philadelphia. We are all impacted by the treatment we receive as U.S. minorities, and spent the summer studying the effects of racial discrimination on students of color at different schools. Through our research, we eventually discovered that students of color can feel on alert and uncomfortable in learning environments in which their backgrounds are not well represented. However, this was not the whole story: we also found that students of color, such as me, who attend more racially diverse schools are more comfortable, feel more welcome, are more relaxed, and enjoy school more. This paper is about how we came to those conclusions.

When we were first put together as a group over the summer, we constructed our research design based on our interest in the treatment of students of color in school 

more racially diverse schools are more comfortable, feel more welcome, are more relaxed, and enjoy school more.

mind were: What are schools and campuses like for students of color? How do they impact students physically and mentally, and how can they be improved? For many students, school is like a second home because they spend nearly a third of their day there. For college students, it can be even more intense because many spend most of their time on campus. But for some of us, the sense of school being a home had begun to dissipate for one main reason: students of color were not being given the equitable and welcoming treatment that their White peers receive. We wanted to explore this issue using research and theories that are important in the study of the minority experience, such as Yosso's idea of cultural wealth (2005) and Critical Race Theory (CRT) (Bell, 1995). We chose these theories because they provide multiple ways for us to think about the experiences of people from minority communities in the United States. For example, cultural wealth relates to how minority students bring important knowledge to schools, which is often underappreciated. Related to this is an important idea that Yosso (2005) refers to as "aspirational capital." Yosso describes aspirational capital as a resource that allows students of color to dream beyond the limits of what seems possible in their difficult circumstances as oppressed minorities. Bringing this mindset to school not only allows students to offer positive ideas to other students, but also encourages students to have the desire to do better in class. CRT was also useful in helping us understand that racism is present both inside and outside schools; it offered a beneficial framework for exploring some of the invisible aspects of society that make people of color feel uncomfortable and that influence the social atmosphere around them. With these perspectives, questions, and ideas in mind, we moved forward with our investigation.

\section{RESEARCH METHODS} While participating in the College Access program, our group turned to many different sources of information to help answer our research questions. Our main method of obtaining an answer to our issues was through the qualitative research method of the interview (Gubrium, Holstein, Marvasti, \& McKinney, 2013). We collected data about the impact of school climates on youth of color by speaking with those students and by recollecting experiences from our own lives. As students 
in the Philadelphia School system, we had many insights and ideas to share about this topic. Our main interview was conducted with a University of Pennsylvania student named Ale Cabrales, who at the time had just finished her first year. Ale had been working with our College Access group and had lots of experience resisting injustice. She grew up as a Mexican immigrant in California and faced hardships in being different from all her peers. She had to endure many struggles because of who she was and did not want anyone else to have to go through what she did. Questions we asked Ale included: "What were your experiences of racism in school and in your own life?" "How do you feel your race has impacted your treatment in school?" and "How do you think schooling for students of color can be improved?"

As well as talking to Ale, we also recalled experiences from our own lives. This involved reflecting throughout the summer weeks on the many times that school had felt safe and homelike or unsafe for us as students of color. Having all seven of us bring at least one experience to the table, along with ways we thought we could have solved those issues, we were able to collect an ample amount of data to address our research questions. Rather than using a survey, we thought that conducting an interview and collecting our own experiences would allow us to bring our backgrounds into the research process in personal ways and help guide us towards more relevant findings. Finally, we were also interested in how life outside school compared to experiences within it-because the full picture of our experiences in schools was not complete without some reflection on our identities in society in general. So, we also asked each other questions about life outside school.

A NALYSIS

To analyze the data from our interview with Ale and our own experiences, we first collaboratively discussed what we found to be key points in Ale's interview. During the interview, we had each written down important points from the conversation that we felt could answer our questions and help support our research. When analyzing our own experiences in Philadelphia

When analyzing our own experiences in Philadelphia classrooms, we began to notice similarities among the stories we shared. We found that we had all experienced some kind of discrimination, either within or outside school.

classrooms, we began to notice similarities among the stories we shared. We found that we had all experienced some kind 
of discrimination, either within or outside school. We therefore drew conclusions from the patterns we saw, asking ourselves: What matches up about the experiences we have had? What can our various anecdotes reflect about the experiences of students of color in various schools? Throughout the process of going through our data, we kept returning to our initial research questions: "What are campuses like for students of color?" "How do they impact students physically and mentally?" and "How can they be improved?" Our results, discussed below, show how complex and important the issue of school climate really is for students of color.

RES ULTS

Our data analysis revealed that students who are in less diverse learning environments feel less comfortable in schools than those who are in more diverse learning environments. One major point that stood out from Ale's interview, for example, was how she said she felt as though teachers generally offered more attention to White males, who were in the majority. In Ale's enrollment year, a majority of 4,409 White students were enrolled at the University of Pennsylvania, while only 1,075 Hispanic students were enrolled. This discrepancy suggests that school was not home-like to Ale because her racial and cultural background was not well represented there (Penn Diversity Facts and Figures, 2018). Ale felt uncomfortable in her school environment. Examining this through the lens of cultural wealth, we believe that if more students like Ale had been enrolled at Penn that year, Ale could have had a more welcoming freshman experience. This matches up with findings from Vijenthira, Ali, and Manograran (2018), who argue in their study about faculty diversity in secondary school settings in Canada and the United States that "a lack of diversity leads to feelings of isolation in students of colour, as well as a lack of differing perspectives for all students to learn from" (p. 44).

Another example of a student facing discrimination in school, but in lower grades, is found in a story told by Kerry Coles. Kerry is currently an African-American 11th grader, and he shared how he felt mistreated and discriminated against in school because of his racial identity. In sixth grade, when Kerry was the only African-American student in his year, he said his White teacher did not believe anything he said and showed a lack of trust in him. Kerry explained that he felt as though his teacher was racist towards him because he was an African-American student, and that he thought she believed that African Americans were criminals and untrustworthy in general. He described how this angered him and made him uncomfortable when his teacher asked him questions in front of 
the class. Other students in our group shared stories similar to Kerry's.

My personal experiences as an Indonesian American attending a diverse school in South Philadelphia shows the other side of the coin: the benefits of a learning environment that welcomes the identities and backgrounds of students of color. I am lucky to be enrolled at a school where the majority of students are Asian American like me. I have no need to adopt an alert mindset-meaning feeling the need to be aware of one's surroundings at all times - at my school. Rather, my school teaches students to be welcoming towards each

I am lucky to be enrolled at a school where the majority of students are Asian American like me. I have no need to adopt an alert mindset-meaning feeling the need to be aware of one's surroundings at all times-at my school.

other's cultures. Knowing that I am accepted really helps with my education. My school also integrates lessons about different folk arts into our education. Students are encouraged to participate in groups in which we learn about the arts from different countries. We are, for example, provided with information about Indonesian Dance, from my own culture, and other art forms, such as African Diaspora, Lion Dance, Chinese Opera, Dan Tranh, and African Step Dance. It brings me comfort to learn in a setting like that.

It is, however, a different world outside school. The students at my school are informed about people who say to immigrants - or people they think are immigrants - "Go back to your country." This specific reality, along with other possible acts of discrimination, is why I have an alert mindset whenever I am outside school. Connecting back to CRT, which states that racism is continuously present, I am subjected to racism when outside my comfortable school environment. My contribution to our group, however, was to share what it is like to be in a welcoming school environment.

I M P L I C A T ION S After about two months of research, our group had some initial findings to help answer our research questions. Based on our analysis of the interview with Ale and our own experiences, we found that students of color can feel worried in their surroundings at various schools in Philadelphia and sometimes develop a mindset of alertness. Our research indicated that students of color have to be more fearful because of what they know could happen to them. Students mentioned being bullied for who they are or having witnessed their peers being 
discriminated against. They did not feel completely accepted or safe in their school environments - a finding that matches up with what has been identified in other studies about minority students in schools (Rankin \& Reason, 2005; Harwood, Huntt, Mendenhall, \& Lewis, 2012). This means that school is very different from home for these students; they do not feel scared or worried at home. We drew this conclusion because, based on the data people shared from experiences in their schools, students of color sometimes feel uncomfortable because of who they are and the situations they are placed in with their peers. Members of my group shared negative experiences with each other, such as facing microaggressions, not having the chance to participate as much as White students in class, and having stares thrown at them for no apparent reason.

These reflections led us to create our own solutions to the issues we observed. It is our dream that schools can be like home for all students. Our first recommendation is to train teachers how to discuss issues of race in class and how to alert students to these kinds of topics. This is a key point because if students are aware of such issues and the harm that could come from them, Our first recommendation is to train teachers how to discuss issues of race in class and how to alert students to these kinds of topics.

they can work to prevent that harm. We also feel that having diverse campuses could make students feel more welcome. Diversity

among students would make all students feel as though they weren't "the only ones" representing particular groups. This could also extend to staff-diversity among teachers and professors allows for the existence of different ideas, experiences, and opinions at a higher level on campus. This will not, however, necessarily lead to a completely equal and welcoming environment-as Vijenthira, Ali, and Manogaran (2018) argue, for example, racism exists even in schools that seem "diverse" because faculty of color do not have the same power as their White peers (p. 48). Still, it is an important start: a culturally diverse staff would also allow students to feel as though they are cared for and understood. Our final recommendation is to stress the importance of having teachers learn about the backgrounds and cultural wealth of their minority students (Yosso, 2005). Simple conversations with students about these topics could lighten their day; they will know through such interactions that they have a teacher who cares about who they are. 
The College Access program through which I conducted this inquiry was facilitated by University of Pennsylvania doctoral students Chloe Kannan and Emily Schwab, educator-activist Olivia Vazquez, and UPenn undergraduate Ale Cabrales. After wrapping up College Access over the summer, some of the youth participants chose to join the year-long research team at the Aquinas Center, which is co-facilitated by Chloe Kannan, Ankhi Thakurta (another doctoral student at Penn), Olivia Vazquez, and UPenn master's student Larry Narron. The youth in this group learned about this issue of in:cite, and some of us accordingly decided to choose to write pieces that addressed the theme of home. I decided to write about my group's research project with College Access last summer and created this piece. I was not alone in the process, though; I was supported by the participants in the group, including Kerry Coles and Erick Perez, and by the group facilitators. I was also extremely supported by Ankhi, who worked many hours helping me put this piece together, guiding me through the writing and revising process.

\section{A C K NOW LE D G M E N T S} I would like to acknowledge most importantly Ankhi Thakurta for helping and supporting me throughout the entire writing and editing process; I would not have been able to complete this piece without Ankhi. I would also like to acknowledge Chloe Kannan, Emily Schwab, Olivia Vazquez, and Ale Cabrales for facilitating the College Access program and making it an enjoyable experience for me.
AUTHOR BIO

Owen Setiawan is a rising ninth grader. He is an Indonesian-American who lives with his brother and two parents in Philadelphia. He has a great passion for reading Harry Potter and hopes to become a journalist someday. 


\section{R E F E R E N C E S}

Bell, D. (1995). Who's afraid of critical race theory? University of Illinois Law Review, (4), 893-910.

Gubrium, J., Holstein, J., Marvasti, A., \& McKinney, K. (2013). The SAGE handbook of interview research: the complexity of the craft. Thousand Oaks, CA: SAGE Publishing.

Harwood, S., Huntt, M., Mendenhall, R., \& Lewis, J. (2012). Racial microaggressions in the residence halls: Experiences of students of color at a predominantly White university. Journal of Diversity in Higher Education, 5(3), 159-173.

Penn Diversity Facts and Figures [Web page]. (2018). Retrieved from https://diversity.upenn.edu/diversity-at-penn/factsand-figures

Rankin, S., \& Reason, R. (2005). Differing perceptions: How students of color and White students perceive campus climate for underrepresented groups. Journal of College Student Development, 46(1), 43-61.

Vijenthira, S., Ali, R., \& Manogran, E. (2018). Unaffirmative actions: lessons on refusal, racism, and youth research. in:cite Journal 1(1), 43-52. Retrieved from: https:// incitejournal.org

Yosso, T. (2005). Whose culture has capital? A critical race theory discussion of community cultural wealth. Race Ethnicity and Education, 8(1), 69-91. 